\title{
Einige Worte über die Benutzung der öffentlichen Sammlungen
}

von

Dr. G. Kra at z.

D

ie Veröffentlichung der Wünsche, welche der Unterzeichnete unter Zustimmung des Vereins, bei einer gegebenen Veranlassung an die Verwaltung des Berliner entomologischen Museums richtete, soll dazu dienen, andere Vereine des In- und Auslandes anzuregen, auch ihrerseits auf eine freiere Benutzung der öffentlichen Sammlungen nach Kräften hinzuwirken. Vor allen Dingen wäre dieselbe für das British Museum wünschenswerth, welches zum Zweck der wissenschaftlichen Bearbeitung auch nicht ein Stück zur Ansicht fortgeben darf, was um so mehr zu bedauern ist, je gröfser die dort aufgehäuften entomologischen Schätze sind. -

Wenn von Seiten der Verwaltung des Berliner entomologischen Museums darauf gehalten worden ist, dafs eine liberale Benutzung desselben von Seiten der Fachgelehrten bei dem Besuche des Museums stattfinden konnte, ist dies mit dem gröfsten Danke anzuerkennen. Je mehr aber eine allgemeine provisorische Ordnung der Insekten anempfohlen wird, welche bei dem Umfange des Materiales noch geraume Zeit in Anspruch nehmen dürfte, je mehr von einer streng wissenschaftlichen Bearbeitung einzelner Gruppen von Seiten der Herren Custoden abgerathen werden mufs (natürlich insoweit ihre Zeit auf dem Museum dadurch in Anspruch genommen wird), um so mehr ist von dieser Seite eine möglichst liberale Benutzung der Museumsschätze von aufsen her zu befürworten.

Unter derselben ist die Versendung der Insekten-Arten, ohne Rücksicht auf die Anzahl der vorhandenen Exemplare, an in- und ausländische Entomologen zum Zwecke der Bearbeitung oder eines gründlichen Artenstudiums zu verstehen.

Den Gelehrten kann bei den vortrefflichen Post- und Eisenbahnverwaltungen im Allgemeinen mit vollem Vertrauen entgegen- 
gekommen werden und hat sich dasselbe bei den Besitzern der meisten gröfseren Sammlungen längst befestigt.

Der Fall einer Veruntreuung oder Verunglückung tritt bei solchen Sendungen so ungemein selten ein, dafs der Schaden, welchen allerdings einmal eine Sendung erleiden könnte, verschwindend klein gegen den Nutzen ist, welcher unserer Artenkenntnifs durch den Vergleich der Typen und dem Museum selbst daraus erwächst, dafs es anstatt einer Menge namenloser Insektenformen kostbare Typen zurückerhält. Soll sich eine öffentliche Sammlung nicht darauf beschränken, durch die Zusammenstellung schöner und auffallender Insektenformen und durch Vorführung der Verwandlungsgeschichte nützlicher und schädlicher Arten die Phantasie, den Sinn und damit das Interesse des gröfseren Publicums für die Entomologie anzuregen, sondern werden viele Tausende von Species ohne Rücksicht hierauf von Staatswegen zusammengehäuft, so kann dies in jetzigen Zeiten unseres Erachtens nur den Sinn haben, die Existenz von Centralstätten für Sammlungen zu sichern, damit dieselben bei ilınen länger und sicherer für eine wissenschaftliche Benutzung erhalten werden, als im Besilze vieler Einzelner.

Das Capital, welches der Staat in solchen Sammlungen zur Förderung der Wissenschaft anlegt, wird um so reichlicher verzinst, je mehr Benutzung das angehäufte Material findet. -

Daher würde es als der gröfste Fortschritt einer Verwaltung zu betrachten sein, wenn sie geradezu darauf achtete, ob bei dem Erscheinen gröfserer Arbeiten die Schätze des Museums mit benutzt wurden und ob die gelehrten Hrn. Custoden bemüht gewesen sind, sich mit den verschiedenen Bearbeitern in die dazu nothwendige, rege Verbindung zu setzen.

Da der Berliner entomologische Verein die Instruktionen nicht kennt, welche für die Mittheilung der Insekten der entomologischen Sammlung an auswärtige Gelehrte gegeben sind, erlaubt sich derselbe bei dieser Gelegenheit die gröfsle Liberalität im wohldurch. dachten Interesse der Entomologen und des Museums auf das Wärmste zu befürworten.

Dem Vorsitzenden dieses Vereins wurde vor einigen Jahren, als er an den ersten Custos der entomologischen Sammlung die Frage richtete, ob er wünsche, dafs die ceylonesischen Staphylinen des Museums in seiner (des Vorsitzenden) Bearbeitung der Staphylinen-Fauna von Ostindien mitbearbeitet würden, noch geantwortet:

Von den Sachen des Museums wird Nichts fortgegeben. 


\section{$2 \mathrm{BHL}$ Biodiversity Heritage Library}

Kraatz, G. 1863. "Einige Worte über die Benutzung der öffentlichen Sammlungen." Berliner entomologische Zeitschrift / herausgegeben von dem Entomologischen Vereine in Berlin 7(102)226-227. https://doi.org/10.1002/mmnd.18630070119.

View This Item Online: https://www.biodiversitylibrary.org/item/36389

DOI: $\underline{\text { https://doi.org/10.1002/mmnd.18630070119 }}$

Permalink: https://www.biodiversitylibrary.org/partpdf/209970

\section{Holding Institution}

Smithsonian Libraries

\section{Sponsored by}

Smithsonian

\section{Copyright \& Reuse}

Copyright Status: Public domain. The BHL considers that this work is no longer under copyright protection.

This document was created from content at the Biodiversity Heritage Library, the world's largest open access digital library for biodiversity literature and archives. Visit BHL at https://www.biodiversitylibrary.org. 